\title{
Ни один язык не может существовать без взаимодействия с другими языками
}

Поль де Синети

DOI: 10.30547/mediaalmanah.6.2020.116119

() Де Синети Поль

руководитель Национального управления по продвижению французского языка и языков Франции, Министерство культуры Франции (г. Париж, Франция)
Для меня большая радость быть здесь, потому что я всем сердцем люблю Россию. И для меня большая честь открывать наш двухдневный семинар в качестве руководителя Национального управления по продвижению французского языка и языков Франции, ответственного за координацию языковой политики, проводимой французским правительством.

В своем выступлении в Институте Франции 20 марта 2018 года Президент Республики Эммануэль Макрон поделился с нами своими масштабными планами по обновлению политики в области французского языка и многоязычия. Действительно, в нашу эпоху глобализации невозможно реализовывать политику в области развития одного языка без разработки политики в отношении других языков. Без активного и целеустремленного продвижения многоязычия нас подстерегает опасность установления мирового моноязычия и обеднения мышления. Именно по этой причине нынешняя встреча, заключительное мероприятие в этом насыщенном для «Трианонского диалога» году, имеет особое значение. И выбранные темы представляют большой интерес.

Каковы же, действительно, общие задачи и общие перспективы политики в отношении развития, статуса и использования наших языков, французского 


\title{
Aucune langue ne saurait exister sans le concert des autres
}

\author{
Paul de Sinety
}

(C) De Sinety Paul

Délégué général à la langue française et aux langues de France,

Ministère de la Culture de France

(Paris, France)

C'est une très grande joie pour moi d'être ici parce que j'aime profondément la Russie. Et c'est aussi un très grand honneur d'ouvrir ces journées de dialogues en tant que Délégué général à la langue française et aux langues de France, responsable de la coordination de la politique linguistique du gouvernement français.

Dans son discours du 20 mars 2018, à l'Institut de France, le président de la République Emmanuel Macron nous a partagé sa vision ambitieuse pour une politique renouvelée de la langue française et du plurilinguisme. Langue française et plurilinguisme : on ne saurait en effet mettre en œuvre une politique de la langue, à notre époque mondialisée, sans concevoir une politique des langues.

Sans promotion active et militante du plurilinguisme, c'est le danger du monolinguisme mondial qui nous guette avec celui de l'appauvrissement de la pensée.

C'est pour cette raison que cette rencontre, dernière manifestation de cette année intense du « Dialogue de Trianon », est parée d'une importance particulière. Et les sujets sont passionnants! Quels sont en effet les enjeux communs et les perspectives partagées des politiques concernant l'aménagement linguistique, les statuts et l'emploi de nos langues, française et russe, que nous mettons en œuvre au sein de nos deux pays ? Comment évaluer les promotions et les développements de nos langues selon les bases juridiques et les mécanismes institutionnels respectifs?

De quelles méthodes, quels leviers, quelles ressources disposons-nous pour faire vivre nos langues, toutes nos langues, le français et le russe, les langues de France, les langues de Russie ? Comment la société civile peut nous accompagner dans nos politiques? Je pense évidemment aux secteurs du numérique, aux réseaux sociaux et aux médias qui sont amenés à y jouer un rôle central. Parmi les autres points que nous aborderons, figurent enfin les statuts internationaux du français et du russe et leur promotion à l'étranger, ainsi que la protection et la valorisation de la riche diversité linguistique propre à nos deux pays. La France compte plus de 75 langues de France, dont un tiers parlé dans les territoires d'outre-mer.

Comme vous le savez-vous sans doute, 300 nouveaux termes français sont forgés chaque année et paraissent dans le Journal officiel de la République 
и русского, которую мы реализуем в наших двух странах? Как оценивать продвижение и развитие наших языков в соответствии с существующими во Франции и в России правовыми основами и институциональными механизмами? Какими методами, рычагами и ресурсами мы располагаем для того, чтобы наши языки - французский и русский, языки Франции, языки России продолжали развиваться? Какую поддержку нам может оказать гражданское общество? Я, конечно, имею в виду цифровые технологии, социальные сети и традиционные средства массовой информации, которые призваны играть в этом центральную роль. Наконец, среди вопросов, которые мы рассмотрим, - международный статус французского и русского языков и их продвижение за рубежом, а также защита и повышение значимости богатого языкового разнообразия, характерного для обеих стран.

Напомним, в этой связи, что каждый год во французском языке создается 300 новых терминов, которые публикуются в «Официальном вестнике Французской Республики». Они образованы от иностранных терминов, в основном англоязычных, и отражают дух современности во французском языке. Позвольте мне выразить надежду на то, что наше дело будет продолжено и два наших прекрасных, живых и современных языка, носителями которых являются новые поколения, смогут ответить на этот постоянный вызов, проявляющийся в необходимости выражать многообразие и сложность нашего мира.

В 2022 году Президент Республики откроет новый Международный центр французского языка в замке Виллер-Котре, расположенном в Валуа, колыбели нашей истории. Это место, в 80 км к северо-востоку от Парижа, имеет основополагающее значение для нашего языка. Именно здесь в 1539 году Франциск I подписал знаменитый Ордонанс Виллер-Котре, в соответствии с которым французский получил статус языка правосудия и права вместо латыни, языка чиновников. Именно благодаря этому важнейшему документу французский язык стал делом государственной важности. ВиллерКотре будет символизировать многообразие французского языка, на котором сегодня говорят более 300 миллионов человек во всем мире. Этот замок также открыт для всех других языков, которые контактируют с французским языком, прежде всего для русского. Ни один язык, как мы знаем, не может существовать без взаимодействия с другими языками.

Мы надеемся увидеть вас в Париже, чтобы продолжить наши дискуссии, и я с большим удовольствием приглашаю вас. 
française. Conçus à partir de termes étrangers, anglais pour la plupart, ils expriment la modernité en français. Permettez-moi de former, ici, le vœu que nos deux langues, belles, vivantes et modernes, portées par de nouvelles générations, poursuivront nos travaux et pourront relever ce défi permanent d'exprimer la diversité et la complexité de notre monde.

En 2022, le président de la République inaugurera la nouvelle Cité internationale de la langue française, au château de Villers-Cotterêts, situé dans le berceau des Valois qui est celui de notre histoire. A $80 \mathrm{~km}$ au nord-est de Paris, il s'agit d'un lieu fondateur pour notre langue. C'est, en effet, là que François ler signa, en 1539, la célèbre Ordonnance de Villers-Cotterêts, qui institue la langue française comme langue de justice et du droit pour s'y substituer au latin, langue des clercs. C'est cet acte décisif qui fit que le français devint une affaire d'État.

Ce château rendra compte de la diversité du français parlé par plus de 300 millions de personnes aujourd'hui dans le monde. Ce château sera également en mesure d'accueillir toutes les autres langues en contact avec le français, à commencer par le russe. Aucune langue, nous le savons, ne saurait exister sans le concert des autres.

Nous espérons vous voir à Paris l'année prochaine pour poursuivre nos échanges et c'est une invitation que j'ai grand plaisir à vous lancer. 